\section{MAN AMONG THE PRIMATES}

The Antecedents of Man

An Introduction to the Evolution of the Primates. By Prof. Sir Wilfrid E, Le Gros Clark. (Edinburgh University Publications: Science and Mathematics Texts, No. 2.) Pp. vii +374 . (Edinburgh : At the University Press, 1959. Distributed by Thomas Nelson and Sons, Ltd., 1959.) 21s. net.

E GROS CLARK'S "Early Forerunners of Man" (1934) is one of the basic studies in primatology ; but it has long been unavailable, the stock having been destroyed by enemy action during the War. It is also now seriously out of date because of the great increase in knowledge of fossil primates during the past quarter-century. The Munro Lectures at the University of Edinburgh in 1953 gave Le Gros Clark occasion to review the whole subject, and he has now published what is essentially a revision of the earlier book, incorporating the substance of these lectures and also discoveries made since 1953.

"The Antecedents of Man" covers the same field and has nearly the same organization as "Early Forerunners of Man". The bulk of the book, as before, comprises a series of chapters on the comparative anatomy of the dentition, skull, limbs, brain, special senses, digestive system, and reproductive system of the primates. All are treated from a taxonomic and phylogenetic point of view. Fossil evidence on the hard parts and endocranium is included. These chapters do not differ greatly from the earlier version but have been well brought up to date. A wholly new introductory chapter on modes and processes of evolution and the interpretation of pertinent evidence is a useful and welcome addition. An older chapter on the reference of the tree-shrews to the primates, a radical idea in 1934 but now widely accepted, has been eliminated, and the evidence has been given where appropriate in other chapters.

The revised final chapter on evolutionary radiations of the primates particularly reflects new palæontological discoveries. Among the earlier forms there is less insistence on a sharp tarsioid-lemuroid dichotomy and on derivation of anthropoids from definite tarsioids. Among the later forms, discovery of the australopithecines and recognition of their nearancestral relationship to man has made the greatest difference. Le Gros Clark was among the first to recognize that relationship, and he has maintained it in the face of polemic criticism. He may be excused a measure of satisfaction, here only faintly expressed, that time and further discoveries have proved him right in the opinion of the great majority of his colleagues. Another extremely important body of discovery since 1934 is abundant Miocene primate material found by Leakey in central Africa and described in large part by Le Gros Clark himself.

The taxonomy of early (Palæocene to Oligocene) primates and their relationships to various primitive insectivore-like groups is now again in a fluid state. From that point of view, this is an unfortunate time to review the group, and this part of the diseussion is already becoming out of date. However, one can scarcely wait for study to stop before summarizing past results.

The book is not written down to a popular audience, but it assumes only minimal knowledge of anatomy and zoology. It might, indeed, be considered somewhat elementary for use as a text-book as suggested by axthor and publisher. For that and also other purposes the absence of a formal reference classification is unfortunate.

There are numerous books, even good books, on fossil man and human origins. This is the only book that places man in true perspective within the whole order Primates and its seventy million years of history. It is an excellent synthesis and summary, and it is warmly recommended. G. G. Simpson

\section{ASPECTS OF AERONAUTICAL SCIENCES}

\section{Advances in Aeronautical Sciences}

Proceedings of the First International Congress on the Aeronautical Sciences, Madrid, 8-13 September, 1958. Edited by Th. von Kármán, A. M. Ballantyne, R. R. Dexter, H. Blenk, H. L. Dryden and M. Roy. Vol. 1 : Pp. viii + 1-562. Vol. 2 : Pp. viii +563-1144. (International Series on Aeronautical Sciences and Space Flight. Division 9: Symposia.) (London and New York: Pergamon Press, 1959.) 200s. net the set of two volumes.

7 HE papers recorded in these two volumes were presented at the first international congress organized by the newly formed International Council on the Aeronautical Sciences, and it is hoped that similar meetings will be sponsored in different. countries every two years or thereabouts.

It would be an impossible task for any one reviewer to comment with authority on more than a few of the papers presented, since they cover an immensely wide range of aeronautical science. Forty-six in number (eight in French, four in German, one in Spanish, the remainder in English) they embrace, inter alia, mathematics and materials, medicine and mechanics, mixed flows and magnetohydrodynamics. There are general surveys of fields of knowledge, and original contributions; the speed-range covered runs from the zero forward velocity of a vertical take-off aircraft to the escape velocity of a satellite. I can therefore do no more than skip through the volumes, noting here and there a paper of particular interest, and finally giving an overall impression.

In the formation of the International Council on the Aeronautical Sciences and the promotion of the congress, financial assistance was received from the Guggenheim Fund for Aeronautics; it is therefore appropriate that the Proceedings open with the first Daniel and Florence Guggenheim Memorial Lecture. It was delivered by Th. von Kármán, and entitled "Some Significant Developments in Aerodynamics since 1946 ". It gives a very readable survey of the subject, ranging through supersonic and hypersonic speeds to Newtonian flow, and then over boundarylayer theory and turbulence. One plea should be quoted: "I believe that a systematic nomenclature and classification of these new branches of combined fluid mechanics, electromagnetic theory, and thermodynamics is yet lacking". One may say 'amen' to that.

There follows a group of papers dealing with various problems of high-speed flight--design, navigation, propulsion, the theory of hypersonic flow; an informative little essay from the pen of Lighthill on the dynamics of a dissociating gas is followed by a substantial paper on American experimental work on hypersonics. Next, three papers concerned with thermal effects on structures and one on oscillatory transonic derivatives appear (the authors being 